\title{
Desenhando nas margens. DiáRIO de CAMPo VISUAl de UMA EXPERIÊnCIA ETNOGRÁFICA
}

Fernando Monteiro Camargo

UNIFESP, São Paulo, Brasil ${ }^{1}$

O objetivo dessa publicação é o de apresentar o Diário de Campo Visual desenvolvido durante minha pesquisa de mestrado, que tem como tema o estudo das relaçôes que diferentes atores estabelecem na e com a cidade. O estudo foi desenvolvido na Rua do Porto, na cidade de Piracicaba, SP, Brasil. No processo de pesquisa, utilizei o equipamento fotográfico e o desenho como recursos para elaborar uma cartografia de minha experiência. Em minha experiência imagética, descobri o pescador, personagem que reúne presente e passado e que sobrevive no barranco do rio Piracicaba.

Palavras-chave: antropologia e desenho, antropologia visual, Brasil

\section{INTRODUÇÃo}

A cidade de Piracicaba fica a $152 \mathrm{~km}$ da capital do estado de São Paulo e possui 364.571 habitantes (IBGE s.d.). Essa cidade é uma referência para os moradores das demais cidades da região que buscam bens e serviços especializados, como comércio, serviços de saúde, atividades artístico-culturais e de lazer. Diferentemente da cidade de São Paulo, que teve o seu processo de urbanização iniciado no século XIX, Piracicaba é uma cidade de médio porte e suas transformações espaciais são fruto de processos recentes, a partir da metade do século XX. Isto se deu, entre outros fatores, pela política federal de incentivo à interiorização da industrialização realizadas nos anos de 1973 e 1975 (Sposito 2004). Essas transformações ocasionaram a proliferação de condomínios fechados, edifícios verticais, shopping centers etc., que ofereceram à cidade formas de sociabilidade que incorporaram o que Simmel (1973) chamou de "modos de vida da metró-

1 Grupo de Pesquisas Visuais e Urbanas da Universidade Federal de São Paulo (Visurb). Contato do autor: camargo.fmc@gmail.com 
pole" e, ao mesmo tempo, "preservaram modos de vida interioranos", ${ }^{2}$ criando uma forma de sociabilidade específica.

A Rua do Porto está localizada na margem esquerda do rio Piracicaba e a três quarteirões do centro comercial da cidade. Ela é palco de inúmeras formas de sociabilidade que se transfiguram com a passagem do tempo e do espaço. Ora é ocupada por aposentados jogando caxeta ou dominó, ora serve de palco para apresentações e exposições artísticas; algumas vezes, vira trajeto de procissão, outras vezes é local de confraternização; também é lugar de turismo gastronômico ou, então, local de passagem para chegar à pista de skate. É ponto de encontro de jovens e local de admiração das águas do rio Piracicaba e de edifícios antigos, reconhecidos como patrimônios históricos da cidade. Já abrigou um engenho de cana de açúcar, olarias, uma indústria de tecidos e fabriquetas de pamonha. Foi local de prostituição, venda de drogas e de crimes que marcaram a cidade. Também é local de estudos históricos, arqueológicos, antropológicos, geográficos, arquitetônicos e urbanísticos. Essa multiplicidade de vivências que a rua oferece motivou a pesquisa de mestrado.

\section{Do PROCESSO ETNOGRÁFICO AO CADERNO de CAMPO VISUAL}

Com o intuito de mapear os usos e ocupações da Rua do Porto, construí, durante a minha pesquisa, um caderno de imagens unindo fotografias e desenhos dessa rua ${ }^{3}$. Esse caderno se aproxima daquilo que Taussig (2011) define como "diário de campo", um álbum de recortes que permite sua leitura e releitura de diferentes formas, podendo encontrar significados e combinações inesperados, no jogo entre acaso e destino, ordem e desordem.

Num primeiro momento, procurei construir meus trajetos realizando uma espécie de registro fotográfico por onde caminhava na Rua do Porto. Após esse trabalho, como que num ritual, chegava à minha casa, descarregava as imagens em meu computador e ficava algumas horas olhando para elas, tentando encontrar ligações, talvez obscuras, nos registros imagéticos.

Foi a partir do momento em que decidi fotografar que passei a olhar para as margens do rio e, por sua vez, para os pescadores. Ao fotografar a cidade criei uma narrativa da memória que quebra com uma discursividade linear e que faz emergir outras imagens e memórias. Depois desse dia, como um arqueólogo, comecei cada vez mais a procurar pelos fragmentos e "vestígios" desse personagem, que parecia ter uma relação específica com a rua.

Encontrei os pescadores não somente pescando, quase imperceptíveis nos barrancos embaixo dos deques de madeira. Sua "identidade" também se reflete no peixe grafitado na parede do Largo dos Pescadores, nos peixes vendidos nos restaurantes, nos bonecos de sucata expostos

2 Por "modos de vida interioranos" compreendo as relações e vínculos de longa data estabelecidos entre moradores da cidade. Vínculos estes que contribuem para o comércio que vende "fiado", para a troca de bens e serviços. Além disso, em Piracicaba a coluna social dos três jornais locais tem grande valor simbólico para os habitantes da cidade e tantos outros traços materiais e comportamentais.

3 O caderno surgiu a partir de um exercício proposto por minha orientadora, Profa. Dra. Andrea Barbosa, no âmbito do Grupo de Pesquisas Visuais e Urbanas na Unifesp (Visurb). Dei continuidade à construção desse caderno durante todo o percurso de pesquisa ocupando lugar central em meu estudo sobre a Rua do Porto. A tarefa iniciou-se no segundo semestre de 2014. 
na Casa do Povoador, nas botas que, nos períodos de cheia, boiam no rio e nos períodos de seca são confundidas com pedras. Outras vezes são seus barcos que estão lá compondo a paisagem ou suas varas de pescar e minhocas vendidas em pequenas casas e mercadinhos. Algumas vezes está nos restos de iscas e materiais utilizados na pescaria deixados pelo barranco; e há as ocasiões em que os pescadores estão liderando momentos da Festa do Divino Espírito Santo, como a Derrubada dos Barcos, ${ }^{4}$ etc.

Comecei a olhar para as imagens que havia produzido em campo e para os pescadores que emergiam da imagem, tentando elaborar montagens unindo desenhos e fotografias. A escolha do desenho se deu uma vez que enxerguei nele a possibilidade de incluir elementos que não havia captado com a câmera nas imagens fotográficas. Além disso, considerei que a antropologia e o desenho são modos de ver e, também, modos de conhecer o mundo. Construí narrativas imagéticas que mostram meu percurso pela Rua do Porto.

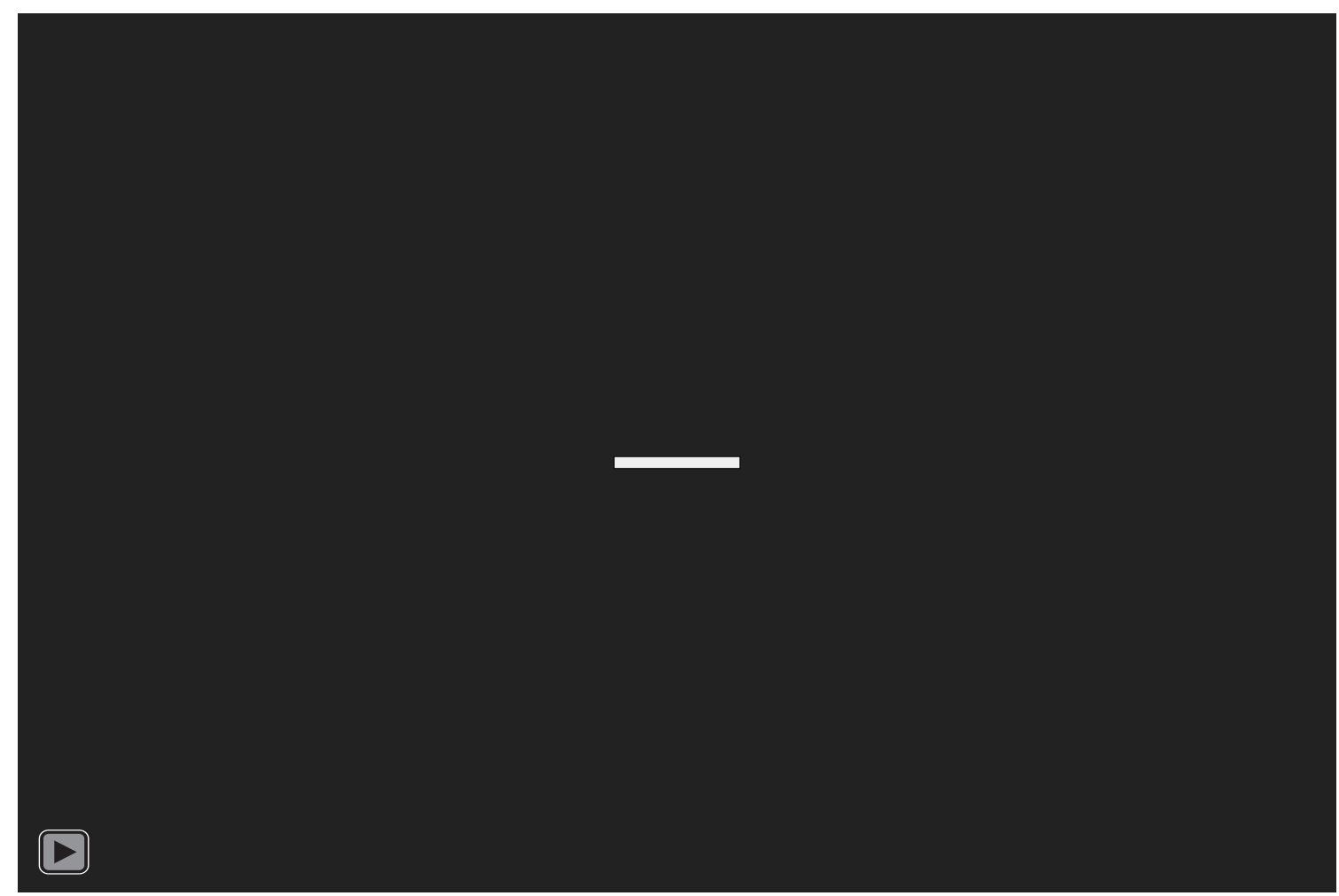

Clicar na imagem para visualizar a galeria de fotos. Desenhos de Laura Lino Mendes da Cruz.

Como não encontrei um caderno ideal como suporte para essas imagens decidi construir um caderno costurando suas páginas. A capa foi feita com uma espécie de papelão encapado com um tecido quadriculado, cinzento. Para as páginas internas utilizei papel Canson (180 gramas) e, para costurar, utilizei uma linha de costura grossa, marrom, de polipropileno.

4 A Derrubada de Barcos é um evento da Festa do Divino Espírito Santo de Piracicaba que ocorre anualmente no primeiro domingo de julho, marcando o início da festa. Nesse evento, após uma missa realizada no salão da Irmandade do Divino de Piracicaba, dois barcos seguem em procissão e, após a bênção de um padre, são colocados nas águas do rio Piracicaba pelos barqueiros do Divino. 
As fotografias, todas de minha autoria, foram impressas em papel couché e em papel 100\% algodão. Imprimi uma dezena de imagens e recortei alguns elementos, por exemplo, pescadores, casas, janelas, pedras, barcos etc. Depois, dispus os elementos sobre as páginas, testando composições e conexões.

A escolha de construir um diálogo entre fotografia e desenho em meu caderno de campo partiu do diálogo entre mim e Laura, minha esposa. Os desenhos, feitos por minha esposa, foram esboçados com lápis grafite $6 \mathrm{~B}$ e depois contornados com caneta nanquim. ${ }^{5}$ Algumas vezes os desenhos surgiram primeiro, para depois as páginas serem completadas com os pedaços das fotografias; outras vezes, os recortes vinham primeiro e os desenhos preenchiam os espaços vazios. Algumas vezes pedia a Laura que desenhasse o que eu não havia fotografado e gostaria que estivesse na imagem; outras vezes ela desenhava aquilo que sentia faltar na imagem. Nas composições, muitas vezes foi necessário criar relações entre as páginas. Dessa forma, criei alguns "vazados" de uma página para a outra. Também precisei sobrepor imagens. Para isso utilizei papel de arroz, que depois de receber os traços, foi colado sobre algumas páginas do caderno.

As sobreposições de papeis e desenhos sobrepõem também temporalidades e espacialidades da Rua do Porto. As linhas desenhadas unem momentos distantes e também distanciam aqueles de maior proximidade. As montagens fizeram com que eu deslocasse meu caminhar direcionado, até então, "para as margens", para um caminhar "nas margens". Eu que sempre andei pelo meio, olhando para as margens, encanto-me com a ideia de andar pelas margens.

No exercício de "montagem, desmontagem e remontagem", procurei explorar as fissuras temporais, os movimentos dos frequentadores e os meus sentimentos, significados e emoções diante da Rua do Porto. As montagens trazem as camadas temporais dessa rua sem esquecer minhas camadas e limitações diante dela. As imagens oferecem possibilidades de explorar, imaginar, sentir, ordenar e desordenar a Rua do Porto. Elas evocam visões, olhares, fantasmas que, por sua vez, despertam lugares e tempos. Os pescadores, que já haviam se destacado em minhas fotografias, ganharam ainda maior destaque. É com eles que eu vou em minhas novas caminhadas.

\section{REFERÊNCIAS}

IBGE - Instituto Brasileiro de Geografia e Estatística. Dados gerais do município de Piracicaba. s.d. Retrieved July, 20, 2015 (http://cidades.ibge.gov.br/painel/painel.php?codmun=353870). Simmel, G. 1973. “A metrópole e a vida mental.” Pp. 11-25 in O fenômeno urbano, edited by O. G. Velho. Rio de Janeiro: Zahar Editores.

Sposito, M. B. E. 2004. "Novos conteúdos nas periferias urbanas das cidades médias do estado de São Paulo, Brasil." in Investigaciones Geográficas, 54: 114-34.

Taussig, Michael. 2011. I swear I saw this: drawings in fieldwork notebooks, namely may own. Chicago e Londres: The University of Chicago Press.

5 Laura não é antropóloga nem desenhista profissional, apenas gosta de desenhar e das pesquisas em antropologia. 


\section{DraWINg AT THE RIVER BANK: A VISUAL FIELD DIARY OF AN ETHNOGRAPHIC EXPERIENCE}

This article presents a visual field diary which was elaborated in the course of the author's research on the relationships of different actors with and within the city. The study took place in Rua do Porto in the city of Piracicaba, São Paulo, Brazil. During the research, photography and drawings were employed as resources to develop a mapping of the fieldworker's research experience. One of the characters discovered during the author's "imagery experience" was a fisherman, an informant who embodies both the city's past and present, surviving on the banks of Piracicaba river.

Keywords: anthropology and drawing, Brazil, visual anthropology

Recebido em: 2016-01-29

Aceitado em: 2016-07-12 